\title{
Modern Trends in Inorganic Chemistry (MTIC-XIII) \\ Foreword
}

This Special Issue is based on the invited lectures delivered at the Thirteenth Symposium on Modern Trends in Inorganic Chemistry (MTIC-XIII) held at the Indian Institute of Science, Bangalore during December 7-10, 2009. The MTIC series of symposia (held once in two years) have emerged as a primary forum for the scientific fraternity of the country to focus on the current status and future projections of research in frontier areas of inorganic chemistry. The topics covered in this issue span a wide range from organometallics, bio-inorganic chemistry, catalysis to materials chemistry that reflect the current trends of research in inorganic chemistry in India.

We thank the Indian Academy of Sciences, Bangalore for agreeing to bring out this special issue and the Editor, Journal of Chemical Sciences for his support and encouragement. We are grateful to the authors for their excellent contributions and reviewers for their timely and valuable help. Thanks are also due to the Journal Editorial Staff for their cooperation and assistance.

8 March 2011

S VASUDEVAN

Department of Inorganic and Physical Chemistry, Indian Institute of Science, Bangalore 560 012, India e-mail: svipc@iisc.ernet.in

G U KULKARNI Chemistry and Physics of Materials Unit, Jawaharlal Nehru Centre for Advanced Scientific Research, Bangalore 560 064, India e-mail: kulkarni@jncasr.ac.in

(Guest Editors) 